\title{
四塩化炭素中におけるアントラキノン染料と 安息香酸エチルとの相互作用
}

\author{
（1973 年 1 月 30 日受理） \\ 喜多村一夫*·古川安*・吉田善一**
}

ポリエステル纎維の染色に括ける㵶維，染料間結合力に関する基礎的知見を得ることを目的として， 四塩化炭素中に打けるアントラキノン染料と安息香酸エチル (EB) との相互作用を, 主としてペーパー クロマトグラフ法により検討した。

$\mathrm{EB}$ の不存在および存在下に括ける染料の $R_{\mathrm{f}}$ 值を $R_{\mathrm{f} 0}$ およ゙゙ $R_{\mathrm{f}}$ とし, 展開剤中に打ける $\mathrm{EB}$ 初 濃度および染料と $\mathrm{EB}$ との錯体生成の平衡定数をそれぞれ $c_{\mathrm{A}}$ および $K_{m}$ ( $m$ は染料に対する $\mathrm{EB}$ 結 合比； $m=1,2, \cdots \cdots)$ とすると

$$
\log \frac{R_{\mathrm{f}}-R_{\mathrm{f} 0}}{\left(1-R_{\mathrm{f}}\right) R_{\mathrm{f} 0}}=\Sigma K_{1} \cdot c_{\mathrm{A}}+\Sigma K_{2} \cdot c_{\mathrm{A}}^{2}+\Sigma K_{\mathrm{g}} \cdot c_{\mathrm{A}}^{3}+\cdots \cdots
$$

の関係があることを導き，これを用いて $\Sigma K_{1}$ および $\Sigma K_{2}$ を求めた。ここで， $\Sigma K_{1}, \Sigma K_{2}$ などは，各 結合比ごとに 2 種以上の錯体生成反応が共存する場合の各結合比ごとの平衡定数の和である。

その結果，通常は染料のカルボニル基とェステル基との双極子間引力による $1: 1$ 型錯体を生成する が，フェノール性水酸基を有する染料では， $1: 2$ 型錯体も生成すること，またこの場合，双極子間引 力による錯体以外飞水素結合錯体も生成し， $\Sigma K_{1}$ が非常に大きくなることなどがわかった。

\section{1 緒 言}

アントラキノン染料と酶酸メチルとは， ジオキサン水溶液中で エステルとカルボニル基との間の双極子間引力による錯体を生成 することがポーラログラフ法により確かめられている1。一方, このような錯体の生成について検討する場合, ペーパークロマト グラフ法が簡単で有効な手段であることも知られている2)。

そこで, ポリェステル織維の染色における紻維一染料間結合力 についての基礎知見を得るため, 㵶維のモデルとしての安息香酸 エチル（以下 EB と略記する）と，これと双極子間相互作用以外 の相互作用も期待されるアントラキノン染料とを用い, 四塩化炭 素中に抽るいろいろの染料-EB 間相互作用について, 主として ペーパークロマトグラフ法を用いて検討することにより，二三の 知見を得たので報告する。

\section{2 実験}

\section{1 試 料}

染料：市販品または既知の方法で合成した染料を，再結晶沶よ びアルミナカラムクロマトグラフ法を併用して精製した(表 1 )。

四塩化炭素, EB およびフェノール：市販の試薬特級を常法に より精製した。

* 帝人株式会社絾維加工研究所, 567 茨木市耳原

** 京都大学工学部, 606 京都市左京区吉田

1）吉田善一, 田尻弘水, 小田良平, 工化, 72, 1537 (1969).

2) 吉田善一, 田尻弘水, 小田良平, 工化, 65, 1067 (1962).

\section{2 展開方法}

展開剤として、水飽和四塩化炭素抢よびこれにいろいろの濃度 の EB を添加したものを用いた。

また展開は，東洋沪紙 No. 50 を用い， $20 \pm 0.5^{\circ} \mathrm{C}$ の定温槽中 で上昇法により行なった。染料のアセトン溶液を $2.5 \sim 3 \mathrm{~cm}$ の 間隔にスポットした沪紙を乾燥したのち, 展開装置にとりつけた。 沪紙の下端が接触しない程度に展開剤を入れ，一夜間放置して装 置内部を平衡状態に達しさせたのち, 展開剤を原点から $1 \mathrm{~cm}$ 下 まで注入して展開を開始し，原点から $15 \mathrm{~cm}$ のところまで展開 した。

テーリングを防止するためスポットする染料濃度をできるだけ 薄くしたので, 自然光のもとでは展開位固を確認できない場合も 生じたが，この場合にはブラックライトを用いてその位置を確認 した。それでも一部にテーリングを生じるスポットがあったが, これらのスポットについては，須田らと同様の方法で $R_{\mathrm{f}}$ 值を算 出した9)。

\section{3 電子スペクトルおよび赤外吸収スペクトルの測定}

電子スペクトルは島津自記分光光度計 MPS $50 \mathrm{~L}$ を，また赤 外吸収スペクトルは日立 Perkin Elmer 125 型赤外分光光度計を 用いて常法により测定した。

\section{3 結果および考察}

\section{1 $R_{p}$ 值の解析法}

沪紙分配クロマトグラフィーに拈いては，一般に式(1)が成立

3）須田昌男, 宇治川秀雄, 織工試研究報告, No. 62, 47(1962). 
することが確かめられている゙)。

$$
R_{\mathrm{f}}=\frac{1}{1+a \frac{c_{\mathrm{f}}}{c_{\mathrm{s}}}}=\frac{1}{1+a k}
$$

ここで $c_{\mathrm{s}}$ および $c_{\mathrm{r}}$ は，それぞれ，移動相および沪紙に保持さ れる固定相中に括ける展開物質の濃度であり，aは沪紙定数であ る。いま展開物質である染料（D）が移動相中で $\mathrm{EB}(\mathrm{A})$ と

$$
\mathrm{D}+m^{\prime} \mathrm{A} \stackrel{K}{\rightleftarrows} \mathrm{DA}_{m^{\prime}}
$$

で示される銷体 $\mathrm{DA}_{m}$ を生成する場合，平衡定数 $K$ は

$$
\log \frac{R_{\mathrm{f}}-R_{\mathrm{f} 0}}{\left(1-R_{\mathrm{f}}\right) R_{\mathrm{f} 0}}=m^{\prime} \log c_{\mathrm{A}}+K
$$

で与えられる2)。ここで $R_{\mathrm{f} 0}$ 扰よび $R_{\mathrm{f}}$ は，それぞれ，EB の不 存在および存在下に括ける染料の $R_{\mathrm{f}}$ 值で, また $c_{\mathrm{A}}$ は展開剤中 の $\mathrm{EB}$ 初濃度である。しかし式 (2) 以外の種類の相互作用が共 存する場合には，当然 $R_{\mathrm{f}}$ 値にその影響が現われてくる。

また一方，- $\mathrm{NH}_{2},-\mathrm{NHR} ，-\mathrm{OH}$ などの置換位置が 1-位である アントラキノン染料と酢酸メチルとの間の相互作用（錯体生成） は, >C=0 と -COO-間の双極子間引力によることがポーラログ ラフ法による実験から明らかにされている1)。これらの染料では, 水素結合性基は分子内水素結合を形成しているため5)，染料をプ ロトン供与体としェステルをプロトン受容体とする水素結合錯体 の生成は無視できるものと考えられるが，ここで検討しょうとす る染料には，表 1 に示したよ5に，このような水素結合錯体の生 成が無視できない染料も含まれている。したがってこれらの染料 については, 双極子間引力による錯体以外に, 水素結合錯体の生

Table $1 \mathrm{mp}, R_{\mathrm{f} 0}, \Sigma K_{1}$ and $\Sigma K_{2}$ of anthraquinone dyes

\begin{tabular}{|c|c|c|c|c|c|}
\hline \multicolumn{2}{|c|}{ Dyes } & \multirow{2}{*}{$\operatorname{mp}_{\left({ }^{\circ} \mathrm{C}\right)}$} & \multirow{2}{*}{$R_{\mathrm{f} 0}$} & \multirow{2}{*}{$\Sigma K_{1}$} & \multirow{2}{*}{$\Sigma K_{2}$} \\
\hline Number & Substituents & & & & \\
\hline 1 & $1-\mathrm{NH}$ & 140.8 & 0.97 & - & 一 \\
\hline 2 & $1-\mathrm{NH}$ & 204 & 0.74 & 5.9 & - \\
\hline 3 & $1-\mathrm{NH}$ & 146 & 0.24 & 15.2 & 0.84 \\
\hline 4 & $1,4-\mathrm{N}$ & 220.8 & 0.97 & - & - \\
\hline 5 & $1-\mathrm{NHCH}_{8}$ & 170.4 & 0.96 & - & - \\
\hline 6 & $1-\mathrm{NHC}_{2} \mathrm{H}_{4} \mathrm{OH}$ & 140 & 0.24 & 5.8 & - \\
\hline 7 & $1,4-\mathrm{NH}_{2}$ & 273.7 & 0.23 & 6.2 & - \\
\hline 8 & $1,4-\mathrm{NHCH}_{3}$ & 221 & 0.93 & - & - \\
\hline 9 & $1,4-\mathrm{NHCOCH}_{3}$ & 286.5 & 0.57 & 4. 4 & - \\
\hline 10 & $1-\mathrm{OH}$ & 200.6 & 0.98 & - & - \\
\hline 11 & $1-\mathrm{OCH}_{s}$ & 171.9 & 0.93 & - & - \\
\hline 12 & $1,4-\mathrm{OCH}_{3}$ & 170.1 & 0.43 & 5.8 & - \\
\hline 13 & $1,4-\mathrm{Cl}$ & 188.7 & 0.96 & - & - \\
\hline 14 & $2-\mathrm{NH}_{2}$ & 308.5 & 0.29 & 6.3 & - \\
\hline
\end{tabular}
tested

Dyes

4) A. J. P. Martin, R. L. M. Synge, Biochem. J., 35, 1358 (1941) ; R. Consden, A. H. Gordon, A. J. P. Martin, ibid., 38, 224(1944).

5）たとえば, D. Hadzi, N. Sheppard, Trans. Faraday Soc. 50, 911(1954); H. Hoyer, Z. Elektrochem., 60, 381 (1956).
成も考虑しなければならない。そこで本報に打いては，移動相中 で 1 種以上の錯体が生成しているという前提のもとに， $R_{\mathrm{f}}$ 値の 㤎化を解析する。

いま，移動相中に括いて $1: 1$ 型錯体の生成する反応が $p$ 個, $1: 2$ 型錯体のそれが $q$ 個，…1: $m$ 型錯体のそれが $r$ 個あるる

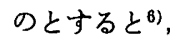

$$
\begin{aligned}
& \mathrm{D}+\mathrm{A} \stackrel{K_{1}(1)}{\rightleftarrows} \mathrm{DA}(1), \cdots \cdots \mathrm{D}+\mathrm{A} \stackrel{K_{1}(p)}{\rightleftarrows} \mathrm{DA}(p) \\
& \mathrm{D}+2 \mathrm{~A} \stackrel{K_{2}(1)}{\rightleftarrows} \mathrm{DA}_{2}(1), \cdots \cdots \mathrm{D}+2 \mathrm{~A} \stackrel{K_{2}(q)}{\rightleftarrows} \mathrm{DA}_{2}(q)
\end{aligned}
$$

一般に，

$$
\mathrm{D}+m \mathrm{~A} \stackrel{K_{m}(1)}{\rightleftarrows} \mathrm{DA}_{m}(1), \cdots \cdots \mathrm{D}+m \mathrm{~A} \stackrel{K_{m}(r)}{\rightleftarrows} \mathrm{DA}_{m}(r)
$$

したがって移動相中の全染料濃度 $c_{\mathrm{g}}$ は

$$
\begin{array}{r}
c_{\mathrm{s}}=[\mathrm{D}]+\{[\mathrm{DA}(1)]+\cdots \cdots[\mathrm{DA}(p)]\}+\left\{\left[\mathrm{DA}_{2}(1)\right]+\cdots \cdots\right. \\
\left.\left[\mathrm{DA}_{2}(q)\right]\right\}+\cdots \cdots\left\{\left[\mathrm{DA}_{m}(1)\right]+\cdots \cdots\left[\mathrm{DA}_{m}(r)\right]\right\}
\end{array}
$$

ところで，EB は実験温度において四塩化炭素とは任意の割合 で混合するが，その水に対する溶解度は $0.0067 \mathrm{~mol} / l$ （ただ熱 時) ${ }^{7)}$ である。したがって, 展開剤中の $\mathrm{EB}$ 濃度約 $1 \mathrm{~mol} / l$ (約 $0.1 \mathrm{~mol}$ 分率) 以下で実験する場合について，単純に分配則を適 用して固定相（水）中における $\mathrm{EB}$ 濃度を試算すると，最大約 $0.00067 \mathrm{~mol} / l$ となる。さらに, 平衡定数も非常に小さい（約 15 $l / \mathrm{mol}$ 以下）から，固定相中に打いては錯体の生成が無視できる ものとし，式 (4)の平衡定数を用いて整理すると

$$
\begin{aligned}
k & =\frac{c_{\mathrm{f}}}{c_{\mathrm{s}}} \\
& =\frac{c_{\mathrm{f}}}{[\mathrm{D}]\left\{1+\sum_{1}^{p} K_{1} \cdot[\mathrm{A}]+\sum_{1}^{q} K_{2} \cdot[\mathrm{A}]^{2}+\cdots \cdots \sum_{1}^{r} K_{m} \cdot[\mathrm{A}]^{m}\right\}}
\end{aligned}
$$

$R_{\mathrm{f}}$ 值と同様に $[\mathrm{A}]=0$ のときの $k$ を $k_{0}$ で表わすと

$$
k=k_{0} \cdot \frac{1}{1+\sum_{1}^{p} K_{1} \cdot[\mathrm{A}]+\sum_{1}^{q} K_{2} \cdot[\mathrm{A}]^{2}+\cdots \cdots \cdot \sum_{1}^{r} K_{m} \cdot[\mathrm{A}]^{m}}
$$

$\mathrm{EB}$ 濃度にくらべ十分小さい染料濃度で展開を行なったとすると， [A] のかわりに $\mathrm{EB}$ の初濃度 $c_{\mathrm{A}}$ が用いられるから

$$
\begin{aligned}
& \frac{k_{0}}{k}-1 \\
& =\frac{R_{\mathrm{f}}-R_{\mathrm{f} 0}}{\left(1-R_{\mathrm{f}}\right) R_{\mathrm{f} 0}}=\sum_{\mathrm{I}}^{p} K_{1} \cdot c_{\mathrm{A}}+\sum_{1}^{q} K_{2} \cdot c_{\mathrm{A}}{ }^{2}+\cdots \cdots \cdot \sum_{1}^{r} K_{m} \cdot c_{\mathrm{A}}{ }^{m}
\end{aligned}
$$

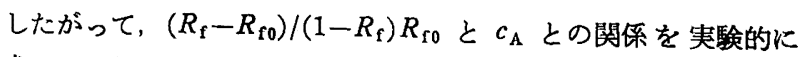
求め, これから式(5) の右辺の係数を推定すればよいが8), ここ では, 次節に述べるように図を用いて求めた。

$3.2 R_{f 0}, \Sigma K_{1}$ および $\Sigma K_{2}$

供試染料の $R_{\mathrm{f} 0}$ 值を表 1 に示した。また，スポットの直径が

6）この場合，EA 1 に対し染料が 2 以上の結合比をとる錯体 の生成は考えがたいが，念のため，式( 3 )のプロットを行 なって $m^{\prime}$ が 1 の非常に近くかあるいはそれ以上であるこ とを確かめた。

7）日本化学会編，“化学便筧(基碟編 I )”, 丸善 (1966) p. 181.

8）この場合， $c_{\mathrm{A}}$ の水準を等間隔にとっておくと，直交多項 式の係数表が利用できる. 


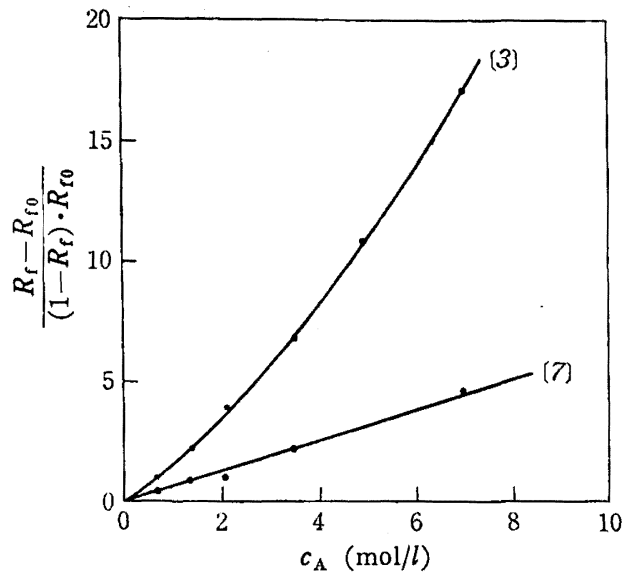

Fig. $1 \quad\left(R_{\mathrm{f}}-R_{\mathrm{f} 0}\right) /\left(1-R_{\mathrm{f}}\right) \cdot R_{\mathrm{f} 0}$ vs. $c_{\mathrm{A}}$

Numbers in the figure show those of dye in Table 1.

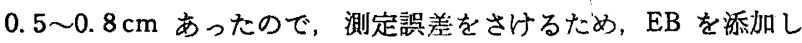
た場合にも展開距離が $14 \mathrm{~cm}$ 以下のスポット（溶剤の展開距離, $15 \mathrm{~cm})$ たけを用いて，EB の添加による $R_{\mathrm{f}}$ 値の変化を調べた。 $\left(R_{\mathrm{f}}-R_{\mathrm{f} 0}\right) /\left(1-R_{\mathrm{f}}\right) R_{\mathrm{f} 0}$ と $c_{\mathrm{A}}$ とをプロットすると, 1-(p-オキ シフェニルアミノ)アントラキノン, 染料 [3]，以外図 1 亿例 示したよらに良好な直線関係が得られたので，これらの染料につ いては，1:1 型以外の錯体は生成していないるのと考えられる。 そこで，この值線の勾配から $\Sigma K_{1}$ を求め，表 1 に示した。また 染料 [3]については，因上微分を行なって d/d $c_{\mathrm{A}}\left\{\left(R_{\mathrm{f}}-R_{\mathrm{fo} 0}\right) /\right.$ $\left.\left(1-R_{\mathrm{f}}\right) R_{\mathrm{f} 0}\right\}$ を求め，これを $c_{\mathrm{A}}$ に対してプロットすると，図 2 に示したよらに良好な直線関係が得られた。したがって,この染 料については $1: 3$ 型以上の錯体は生成していないるのとみなさ れるから，この直線の切片および勾配からそれぞれ $\Sigma K_{1}$ および $\Sigma K_{2}$ を求めた。

このよらにして得られた $\log \left(\Sigma K_{1}\right)$ と，可視部に拈ける四塩 化炭素またはクロロホルム中の極大吸収波長”)とのプロットを四 3 に示したが， $\log \left(\Sigma K_{1}\right)$ と極大吸収波長との間には，分子内水

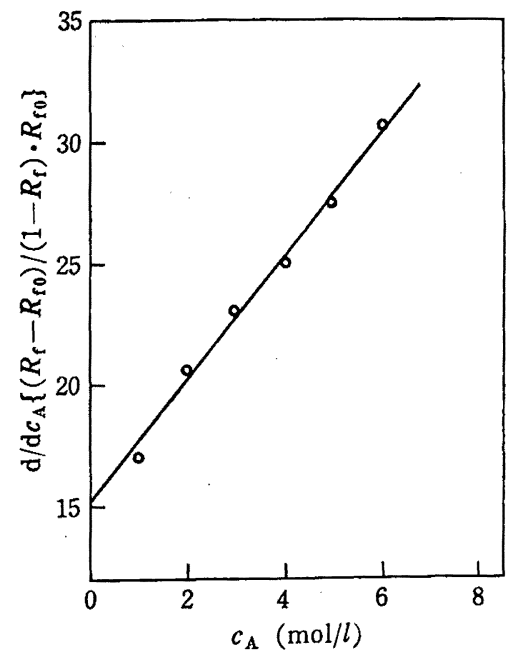

Fig. $2 \mathrm{~d} / \mathrm{d} c_{\mathrm{A}}\left\{\left(R_{\mathrm{f}}-R_{\mathrm{f} 0}\right) /\left(1-R_{\mathrm{f}}\right) \cdot R_{\mathrm{f} 0}\right.$ vs. $c_{\mathrm{A}}$ for dye [3]

9）染料别の使用溶媒は表 2 飞示されている。また，染料 [6] の使用溶媒は四塩化炭素である。

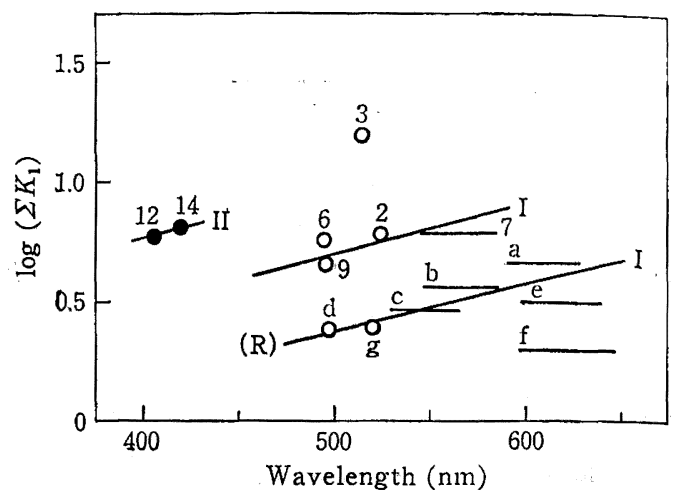

Fig. $3 \log \left(\Sigma K_{1}\right)$ vs. absorption maxima of anthraquinone dyes

$O$ : Dyes which can form intramolecular hydrogen bonding (dye group I)

- Dyes which do not form intramolecular hydrogen bonding (dye group II)

Plots in ( $R$ ) are literature values ${ }^{1)}$ measured by polarography.

Numbers in the figure show those of dye in Table 1 and alphabet anthraquinone dyes having following substituents.

a : $1,4,5,8-\mathrm{NH}_{2}, \quad$ b : $1,4-\mathrm{NH}_{2}, \quad$ c : $1,4-\mathrm{NH}_{2}, \quad 2-\mathrm{OCH}_{8}$, $\mathrm{d}: 1-\mathrm{NHCH}_{3}$, e : $1-\mathrm{NHCH}_{3}, \quad 4-\mathrm{NH}-\phi$, f : $1,4-\mathrm{NHCH}_{3}$, $\mathrm{g}: 1-\mathrm{NH}_{2}, 4-\mathrm{OH}$

素結合を形成しうる染料群（I）とそうでない染料群（II）とにつ いて，染料〔3]以外，それぞれ直線関係が認められた。な拈， 図 3 では複数の吸収極大を有する染料については，その間を線で 結んであらわした。また，参考のため $40 \%$ ジオキサン（60\%は Britton-Robinson 緩衝液) 中に打けるI群に属する染料之酢酸 メチルとの錯体生成のポーラログラフ法による平衡定数（文献 值 $)^{1)}$ と極大吸収波長との関係も同洔に示したが，I 群の染料の 直線に近接して平行する直線関係が得られた。

ところで，㯰換アントラキノン類の可視部に扣ける吸収带は， 置換基からアントラキノン核への分子内電荷移動吸収帯とされて

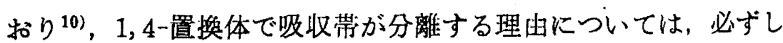
も明確でないけれどす ${ }^{11)}$ ，極大吸収波長は，值換基からアントラ キノン核への電荷移動の程度に依存するすのと考えられる。事些， 置换基の電子供与性が増すほど，深色移動することが認められて いる10)。

したがって，因3で直線にのる染料については， $\Sigma K_{1}$ は直尖基 からアントラキノン核への電荷移動の程度が增すほど大きくなる ものとみなされる。一方， $\log \left(\Sigma K_{1}\right)$ と極大吸収波長との関係は， $40 \%$ ジオキサン水溶液中に拈けるカルボニル基の半波電位を酢 酸メチルの存在怙よび不存在下で測定することによって求められ た，エステル基とキノン型カルボニル基との間の錯体生成の平衡

10）たとえば, R. H. Peters, H. H. Sumner, J. Chem. Soc., 1953, 2101 ; Z. Yoshida, F. Takabayashi, Tetrahedron, 24, 933(1968).

11）たとえば，1４-ジアミノアントラキノンの長波長部の 2 四 収带の二色性を調へた例がある

12) H. Labhart, Chimia, 15, 20(1961); “Advances in Molecular Spectroscopy”, edited by A. Mangini, Macmillan Co., New York (1962) Vol. 1, p. 255. 
定数の刘数と極大吸収波長との関係1) とたがいに平行関係にあ る。かつ，これらの平衡定数は極大吸収波長とともに增加してい るから， $\Sigma K_{1}$ は，㯰換基からアントラキノン核への電荷移動が 大きくなるほど相互作用力が強くなるよらな，エステル基とカル ポニル基との相互作用に関するものであることが示唆される。し たがって，図3で沮線にのる染料については， $\Sigma K_{1}$ は，主とし て，カルボニル基とエステル基との間の双極子間力による錯体生 成関寸るものと推察され，その結果，実際には $\Sigma K_{1}$ でなく， 単に $K_{1}$ であらわされる性質のものと考兄られる。な拉，I群の 染料と II 群の染料とで別の直線関係が得られた理由についてはあ とで考察する。また，I群の染料について，40\% ジオキサン水 溶液中で眽酸メチルと相互作用する場合 ${ }^{1)}[$ 図 3，(R)]より，四 塩化炭素中で EB と相互作用する場合 (本実験) の方が, 同一極 大吸収波長に対応する $\log K_{1}$ が大きくなった。これは，染料括 よびェステルに対する溶媒和は，40\% ジオキサン水溶液中に括 ける方が強く，またエステルのカルボニル基の極性は $\mathrm{EB}$ の方が 強いことなどによるものと思われるが, その理由は明らかでない。

これに対し, 染料〔3]は水素結合能が大きいフェノール性水 酸基を有するから，双極子間引力による錯体の生成と，水素結合 による錯体の生成の平衡定数がいずれも $\Sigma K_{1}$ に寄与しているた

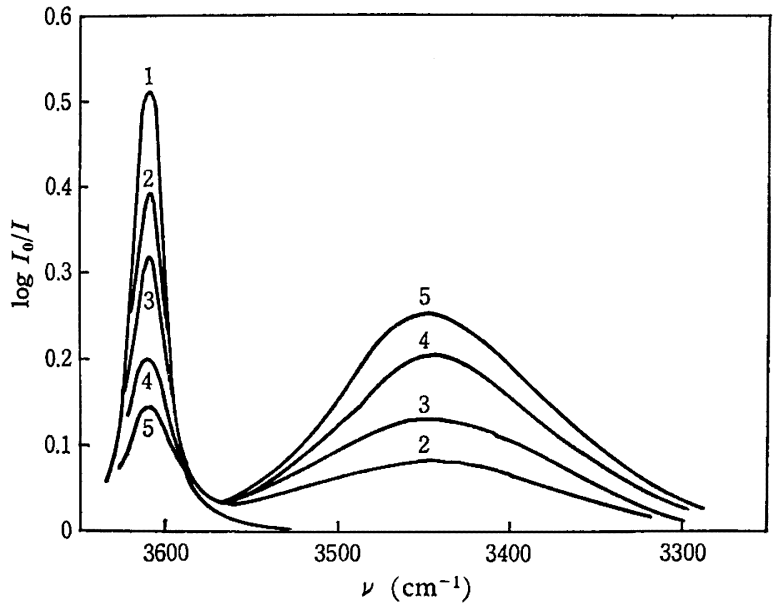

Fig. $4 \mathrm{OH}$ stretching absorption spectra of phenol in the absence or presence of $\mathrm{ES}$ in $\mathrm{CCl}_{4}$ at $20^{\circ} \mathrm{C}$

Concentration of phenol $: 0.010 \mathrm{~mol} / \mathrm{l}$

Concentration of $\mathrm{ES}(\mathrm{mol} / \mathrm{l})$

(1) : 0, (2) :0.0398, (3) :0.080, (4) :0.241, ( 5$): 0.400$
め，直線から大きくずれたるのと考えられる。

そこでこれを証明するため，染料〔3]の四塩化炭菜溶液に $\mathrm{EB}$ を加えた場合の $\mathrm{OH}$ 伸縮振動スペクトルの変化を調べようと したが，染料の溶解度が低く不可能であった。この染料のNの電 于密度はカルポニル基との共役のため低下しているすのと考えら れる。そこで染料 [3]のかわりにフェノールを用い, 四塩化炭 素中に打ける $\mathrm{EB}$ との水素結合錯体の生成を検討した。図 4 に $\mathrm{EB}$ の存在および不存在に拈けるフェノールの $\mathrm{OH}$ 伸縮振動スペ クトルを示した。これから水素結合錯体生成の平衡定数を求める と $7.2\left(20^{\circ} \mathrm{C}\right)$ であった。そこで $\log \left\{\left(\Sigma K_{1}\right)-7.2\right\}$ を計算し困 3 のプロットを行なってみると，I群の直線の近くにくることが わかった。このことは, 染料とフェノールとの違いはあるけれど も， $\Sigma K_{1}$ が, 水素結合と双極子間引力による錯体生成の平衡定 数の和にほぼ相当することを示す一つの根拠になるすのと考えら れる。

また染料 [3]の $\Sigma K_{2}$ に対しては， $1: 2$ 型の双極子間錯体, $1: 1$ 型の双極子間錯体と水素結合錯体の組み合わせなどが考え られるが，その内容は明らかでない。しかしいずれにせよ， $\Sigma K_{2}$

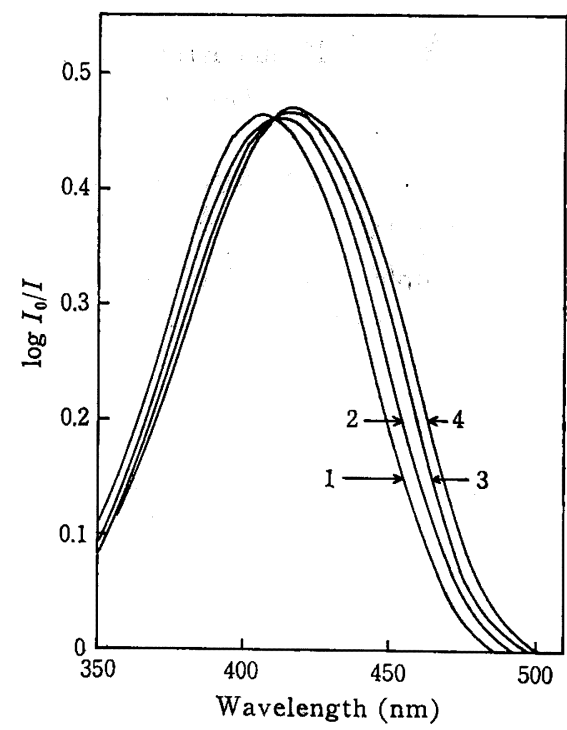

Fig. 5 Visible spectra of 1,4-dimethoxyanthraquinone in the absence or presence of $\mathrm{EB}$ in $\mathrm{CCl}_{4}$ at $20^{\circ} \mathrm{C}$

Concentration of dye : $1.00 \times 10^{-4} \mathrm{~mol} / \mathrm{l}$

Concentration of $\mathrm{EB}(\mathrm{m} l / \mathrm{m} l)$

(1) : 0, (2) :25/100, (3) :50/100, (4) :75/100

Table 2 Absorption maxima of anthraquinone dyes in the absence or presence of ethyl benzoate (EB) in $\mathrm{CCl}_{4}$ or $\mathrm{CHCl}_{3}$

\begin{tabular}{|c|c|c|c|c|c|c|c|}
\hline \multirow[b]{2}{*}{ Dyes $^{a)}$} & \multirow{2}{*}{$\begin{array}{r}\text { Dye concen- } \\
\text { tration } \\
(\mathrm{mol} / \mathrm{l}) \times 10^{4}\end{array}$} & \multirow[b]{2}{*}{ Solvents } & \multicolumn{4}{|c|}{ Maxma in $\mathrm{nm}$ on various $\mathrm{EB}$ concentration } & \multirow[b]{2}{*}{$\begin{array}{l}\text { Isosbestic } \\
\text { point }\end{array}$} \\
\hline & & & 0 & $\begin{array}{c}25 \mathrm{ml} / \\
100 \mathrm{ml}\end{array}$ & $\begin{array}{l}50 \mathrm{mll} \\
\quad 100 \mathrm{ml}\end{array}$ & $\frac{75 \mathrm{ml} /}{100 \mathrm{~m} l}$ & \\
\hline 2 & 1.00 & $\mathrm{CHCl}_{3}$ & 525 & - & 525 & - & Not observed \\
\hline 3 & 1.00 & $\mathrm{CHCl}_{3}$ & 515 & - & 516 & - & Not observed \\
\hline 7 & 1.00 & $\mathrm{CCl}_{4}$ & $\begin{array}{l}545 \\
584\end{array}$ & $\begin{array}{l}550 \\
588\end{array}$ & $\begin{array}{l}553 \\
591\end{array}$ & $\begin{array}{l}553 \\
592\end{array}$ & Not observed \\
\hline 9 & 1.00 & $\mathrm{CCl}_{4}$ & 497 & 495 & 494 & 494 & Not observed \\
\hline 12 & 1.00 & $\mathrm{CCl}_{4}$ & 407 & 411 & 415 & 418 & Observed \\
\hline 14 & 1.00 & $\mathrm{CHCl}_{3}$ & 420 & 427 & 430 & 432 & Observed \\
\hline
\end{tabular}

a) Dye numbers correspond to those listed in Table 1 . 
は非常に小であった。

つぎに、I 群の染料と II 群の染料とで別の直線が得られた理由 を考察する。いま問題としている分子内電何移動吸収帯に括いて

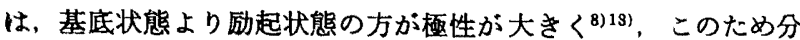
子内水素結合屾基底状態より励起状態の方をより安定化する結果, 染色効果を示す。したがって，置換基からアントラキノン核への 電荷移動の程度が同じでも，分子内水素結合の有無によって，極 大吸収波長が異なることになるが，このことが別の直線関係が得 られたすっとも大きい理由と考えられる。

\subsection{EB の添加による可視吸収スペクトルの変化}

染料の四塩化炭素溶液またはクロロホルム溶液 ${ }^{14)}$ に EB.を加 えた場合の㓙大吸収波長の変化を表 2 に示した。また，等吸収点 が明瞭に観察されるかどらかす示した。

13) G.C. Pimentel, J. Amer. Chem. Soc., 79, 3323(1957).

14）四塩化炭素に対する溶解度が小さく，測定困難な染料沱は クロロホルムを用いた。
I 群の染料は一般に極大吸収波長の移動が少ないが，II群の染 料は深色移動し，かつ明暸な等吸収点が観察された。 $\mathrm{EB}$ と染料 のカルボニル基とが双極子間引力によって相互作用するものとす ると，極性の大さい励起状態をより安定化するため，深色移動す るものと考えられる。またI群の染料の場合, 波長移勘が少ない のは，分子内水素結合による安定化の笴与が大きく， EB の影踾 が現われなかったためか，あるいはとくに 1-直換体の場合，分 子内電荷移動スペクトルに関与しない方のカルポニル基が，主と してェステルとの相互作用にあずかっているためであるかは明ら かでないが，これらの点については，今後の詳細な検討が必要で ある。

1,4-ジメトキシアントラキノンのスペクトルを図 5 に示した。 等吸収点は化学量論的な錯体の生成を意味するが，この染料の場 合, これは染料のカルボニル基とエステル基との双極子間引力に よる錯体生成を裏づけるるのであろう。

\title{
The Interactions between Anthraquinone Dyes and Ethyl Benzoate in Carbon Tetrachloride
}

\author{
Kazuo Kitamura*, Yasu Furukawa* and Zen-ichi Yoshida** \\ * Fiber and Textile Research Institute, Teijin Ltd. ; \\ Ibaraki-shi 567 Japan \\ ** Department of Synthetic Chemistry, Faculty of Engineering, \\ Kyoto University ; Sakyo-ku, Kyoto-shi 606 Japan
}

The complex formation between anthraquinone dyes and ethyl benzoate (EB) in carbon tetrachloride was investigated by paper chromatography. The equilibrium constants of the complex formation were calculated from the following relation,

$$
\log \frac{R_{\mathrm{f}}-R_{\mathrm{f} 0}}{\left(1-R_{\mathrm{f}}\right) \cdot R_{\mathrm{f} 0}}=\sum K_{1} \cdot c_{\mathrm{A}}+\sum K_{2} \cdot c_{\mathrm{A}}^{2}+\sum K_{3} \cdot c_{\mathrm{A}}{ }^{8}+\cdots \cdots
$$

where $R_{\mathrm{f}}$ and $R_{\mathrm{fo}}$ are the $R_{\mathrm{f}}$ values of dyes in the eluent of $\mathrm{CCl}_{4}$ in the presence of EB and in its absence, respectively. And $\sum K_{1}, \sum K_{2}, \cdots \cdots$ are the sums of equilibrium constants in each complex formation of $1: 1,1: 2, \cdots \cdots$ (dye:EB), respectively. $c_{\Lambda}$ is the initial concentration of $\mathrm{EB}$ in the eluent.

Only a 1:1 complex was observed for the most dyes, and the dipole-dipole interaction between $>\mathrm{CO}$ of dye and -COO- of EB was suggested by spectral investigation. $\mathrm{A} 1: 1$ and a 1:2 complex were observed for the dye having phenolic $\mathrm{OH}$, and this dye had much larger $\sum K_{1}$ than the other dyes, due to the hydrogen bonding between the dye and EB. 